\title{
O PASSEIO PÚBLICO DO RIO DE JANEIRO NA LITERATURA, NA PINTURA E NA FOTOGRAFIA DO SÉCULO XIX ${ }^{1}$
}

\author{
THE PASSEIO PÚBLICO OF RIO DE JANEIRO IN 19TH CENTURY LITERATURE, \\ PAINTING AND PHOTOGRAPHY
}

\section{Solange de Aragão}

Arquiteta, urbanista, mestre e doutora pela FAUUSP, com pós-doutorado em História pela FFLCHUSP. Pesquisadora do Núcleo de Estudos da Paisagem, com apoio do CNPq - Conselho Nacional de Desenvolvimento Científico e Tecnológico (Brasil).

e-mail: solangedearagao@hotmail.com.

\section{Euler Sandeville Júnior}

Professor do Departamento de Projeto da FAUUSP, vice-coordenador da Área Paisagem e Ambiente do Programa de Pós-Graduação em Arquitetura e Urbanismo da USP, e coordenador do Mestrado do Programa em Ciência Ambiental da USP.

e-mail: esandeville@gmail.com. URL: http://espiral.net.br

\section{RESUMO}

Este artigo tem como objetivo geral e mais amplo chamar a atenção dos pesquisadores para a importância da literatura, da pintura e da fotografia como fontes documentais para a construção da História do Paisagismo no Brasil por meio de um estudo de caso muito particular: o Passeio Público do Rio de Janeiro no século XIX.

São objetivos específicos apresentar e analisar o modo como esse espaço livre público aparece na literatura, na pintura e na fotografia desse período, considerando suas transformações paisagísticas.

Palavras-Chave: Passeio Público, Século XIX, Literatura, Pintura, Fotografia

\begin{abstract}
This article has as its main and more general objective catch researcher's attention to the role of literature, painting and photography as documental resources for the construction of Brazilian Landscape Architecture History, by means of a very particular case study: the Passeio Público of Rio de Janeiro in the 19th century. As specific objectives we have the analysis and presentation of this open space in literature, painting, and photography from this period, taking into account its landscape architectural transformation.
\end{abstract}

Keywords: Passeio público, 19th century, Literature, Painting, Photography 


\section{INTRODUÇÃO}

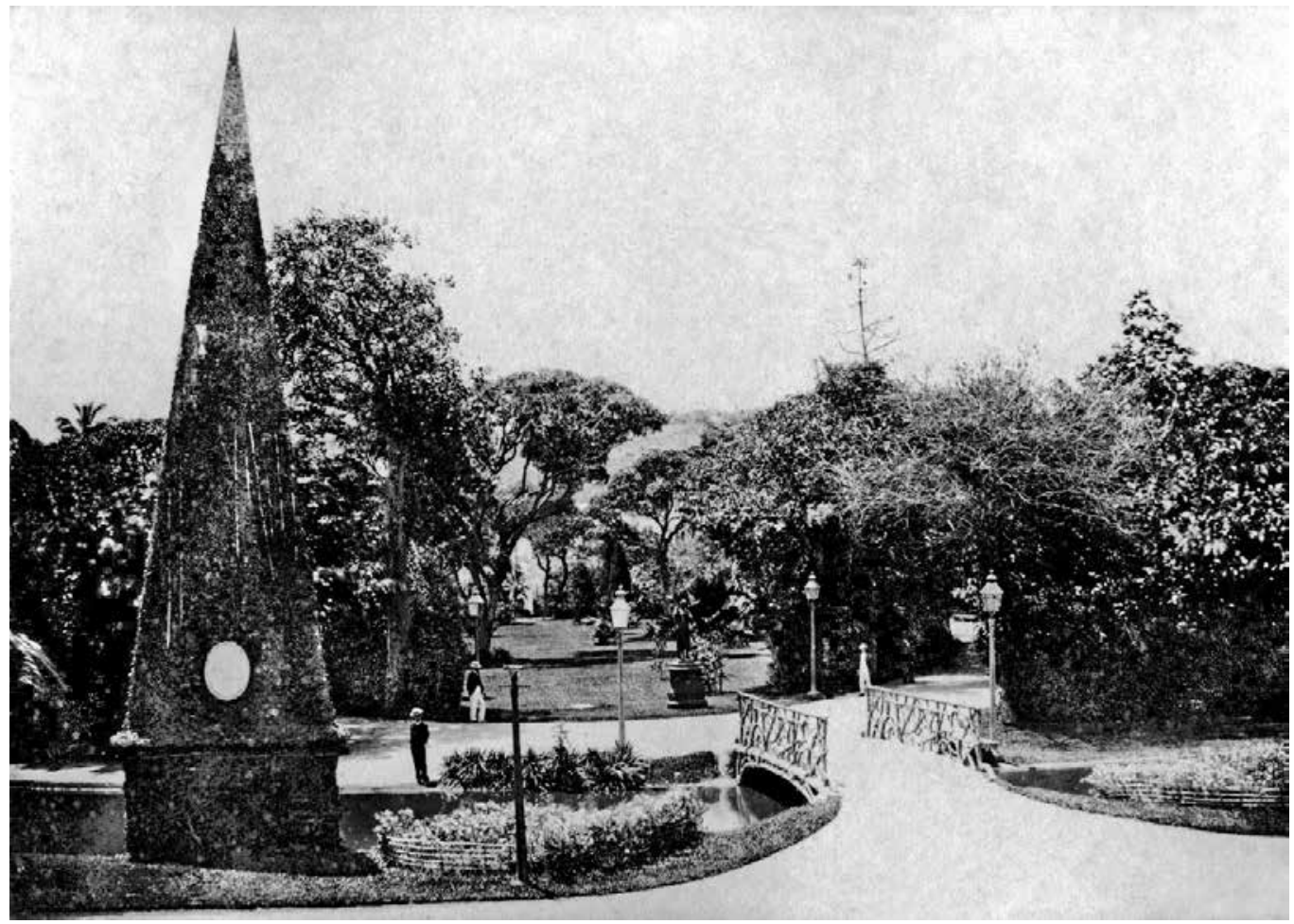

Figura 1 - O Passeio Público do Rio de Janeiro em 1868, com uma das pirâmides do antigo projeto de Valentim. Passeio Público, c. 1868. Rio de Janeiro - RJ.

Crédito: Camilo Vedani / Coleção Gilberto Ferrez / Acervo Instituto Moreira Salles.

"Ao amor do público". Este é o título que Hugo Segawa escolhe para sua obra sobre os jardins públicos no Brasil. Corresponde exatamente à inscrição de uma das pirâmides do antigo projeto de Mestre Valentim, idealizadas para o Passeio Público do Rio de Janeiro.

Esse espaço, importante para o Rio de Janeiro do século XIX, seja pelos usos que proporcionava (caminhadas, conversas, usufruto dos jardins e das áreas sombreadas pelas árvores frondosas, contemplação do mar, da cidade, da paisagem e dos canteiros ajardinados e arborizados), seja pelo significado que adquiriu dentro da malha urbana, foi registrado em textos literários, pinturas e fotografias do período - além, evidentemente, dos relatos de viagem em que muitas vezes se enfatizava o número restrito de usuários apesar de todas as possibilidades de uso e da ideiaideia motriz de sua concepção como local de sociabilidade.

Sua história começa em fins do século XVIII, o "Século das Luzes" na Europa, quando se difundia a ideia da criação de jardins públicos - "símbolos do pensamento iluminista a invocar formas de sociabilidade nas quais a aristocracia e a burguesia encontravam um lugar comum" (SEGAWA, 1996, p.108). Murillo Marx se refere, de modo semelhante, à 
criação dos jardins públicos no Brasil como "reflexo do iluminismo e da expansão dos maiores centros urbanos, no fim do período colonial" (MARX, 1980, p.61). O próprio traçado do Passeio Público do Rio de Janeiro só pode ser explicado sob o viés iluminista e sob a ótica da influência francesa, especialmente no desenho do eixo principal e das alamedas em diagonal.

No Brasil, a substituição do marquês de Lavradio por Luís de Vasconcelos, vicerei a partir de 1779, foi amplamente favorável à criação desse espaço. A ideia de se criar um Passeio Público no Rio de Janeiro à semelhança do Passeio Público de Lisboa (projetado em 1764 por Reinaldo Manuel, remodelado em 1834 por Malaquias Ferreira Leal e destruído em 1879 para abertura da atual avenida da Liberdade) partiu de Luís de Vasconcelos, que encarregou mestre Valentim da Fonseca e Silva do traçado e execução do projeto. Sua implantação correspondeu a um "requinte de civilização urbana" em uma cidade ainda caracteristicamente colonial (MARX, 1980, p.61), pois ainda em 1783, o Passeio foi aberto ao público. Para Murillo Marx (1980, p.61), foi "o primeiro e o mais elaborado jardim de uma série de outros como os de Belém, de Olinda, de Vila Rica e de São Paulo".

De acordo com Hugo Segawa, não são conhecidos registros em relação à data ou a eventuais festejos de abertura (SEGAWA, 1996, p.96) e a observação de desenhos e pinturas revela que, apesar da sofisticação do traçado, era um lugar relativamente simples com as ruas internas sem qualquer tipo de pavimentação. $O$ fato é que, depois de inaugurado e particularmente "passada a administração de seu criador, D. Luís de Vasconcelos", como assinala Segawa (1996, p.98), pouco se fez no sentido de se preservar esse espaço público, que ficou à mercê das intempéries e da violência das ondas do mar, que destruíram parcialmente o terraço - um dos trechos mais agradáveis do projeto pela visão da paisagem marítima que proporcionava.

Após décadas de descaso e de quase total ausência da manutenção, o Passeio foi remodelado por Glaziou no início da década de 1860 - quando perdeu seu traçado original, adquirindo contornos de um paisagismo à inglesa, configurado então pelo predomínio de linhas curvilíneas. Posteriormente, passou por novas reformas sob a direção de Francisco Pedro Fialho, estando muito descaracterizado em princípios do século XX, com relação ao que fora em meados do século XIX (FLEIUSS, 1928, p. 216-7). Não obstante, diferentemente do projeto original, de mestre Valentim, o projeto de Glaziou foi preservado e o Passeio Público permanece na malha urbana do Rio de Janeiro até os dias de hoje - ainda que sem a vista original da baía em consequência dos aterros realizados ao longo do século XX (com o desmonte de alguns morros), que $o$ distanciaram do mar e modificaram a paisagem do entorno (v. SANTUCCI, 2006).

\section{O PASSEIO PÚBLICO NA LITERATURA}

É possível encontrar referências ao Passeio Público do Rio de Janeiro em fontes documentais como os anúncios de jornal: 
"Aluga-se a casa da rua do Passeio n.15, tendo muitos cômodos, cocheira e quintal; quem a pretender, dirija-se à rua dos Ourives n.38." Jornal do Comércio, 20.02.1853. Fundação Biblioteca Nacional. Acervo do Instituto de Estudos Brasileiros - IEB-USP. (grifo nosso)

E relativamente comum encontrá-las em relatos de viagem como os de John Luccock e John Barrow (v. SEGAWA, 1996, p.88) e na construção da História do Brasil por estrangeiros como em History of Brazil, de Andrew Grant, publicado em 1809 ( $v$. GRANT, 1809, p.131-5).

$\bigcirc$ Passeio Público era parte da paisagem do Rio de Janeiro em princípios do século XIX e já estava incorporado à memória de seus cidadãos, passando a ser descrito e referido nas crônicas, memórias e romances produzidos no período, ratificando o caráter documental da literatura também neste caso - da História do Paisagismo ou da Paisagem Brasileira.

Em Um passeio pela cidade do Rio de Janeiro, texto em tom de crônica, mas também de cunho memorialístico, publicado em 1862, Joaquim Manuel de Macedo dedica um capítulo inteiro ao Passeio Público do Rio de Janeiro. $\bigcirc$ autor principia situando o leitor "no aprazível terraço do Passeio Público", sentado sobre os bancos de mármore e azulejo, com as costas voltadas para o mar (MACEDO, 2005, p.79). Desse modo, registra, já no início, algumas características do lugar: a existência de um terraço junto ao mar, com bancos de mármore e azulejo. Em seguida, o autor propõe uma retomada do passado, indo buscar "no último quartel do século décimo oitavo o princípio da história deste jardim público" (MACEDO, 2005, p.80). E de fato reconta essa história, desde a ideia de Luís de Vasconcelos e Sousa, que substituiu o marquês de Lavradio no governo do Brasil em 1779, até a execução do projeto de mestre Valentim e as posteriores alterações propostas por Glaziou em meados do século XIX. Macedo escreve como que elabora um romance, imaginando diálogos a partir das lendas e mitos que envolvem a criação do Passeio, mas por outro lado revela a situação real que acabou resultando na ideia de se criar uma área ajardinada junto à antiga lagoa do Boqueirão - "formada pelas águas da chuva que ficavam estagnadas (...) e, na opinião de muitos, passava por ser um foco de peste" (MACEDO, 2005, p.85). Revela também uma parte da história de vida do mestre Valentim - filho de português com brasileira, educado em Portugal, que se "tornou arquiteto e entalhador de primeira ordem" (MACEDO, 2005, p.83), evidenciando seu papel na criação do Passeio Público: "- Mestre - disse-Ihe o vice-rei (...). Já temos onde aproveitar a terra do desmoronamento do monte das Mangueiras. É na lagoa do Boqueirão, que vamos transformar em um jardim público. Dei a um engenheiro as ordens para tratar imediatamente de fazer esgotar essa lagoa. O jardim fica por sua conta." (MACEDO, 2005, p.94) Apesar de romancear os fatos, Joaquim Manuel de Macedo registra o emprego da terra resultante do desmoronamento do monte das Mangueiras na área onde seria implantado o Passeio.

Um dos trechos mais importantes desse texto, pelo seu valor histórico e de registro, é o que apresenta a descrição do Passeio Público em seu traçado original: 
"O Passeio Público, no espaço que compreendia, representava um hexágono de lados irregulares. Tinha, porém, de frente, na rua do seu mesmo nome, cerca de oitenta e seis braças, e de fundo, do portão da entrada até o gradil do terraço, dando sobre o mar setenta e quatro braças e sete palmos. Ficava-lhe a um lado, que era o da mão direita de quem entrava pelo portão, o largo da Lapa, e ao outro o largo da Ajuda, e, como apenas ficou indicado, corria-lhe pela frente a rua do Passeio, que ligava aqueles dois largos, e no fundo terminava acima do mar por um elegante terraço cuja base recebia às vezes os beijos, às vezes os embates violentos das ondas, ou namoradas ou embravecidas." (MACEDO, 2005, p.102)

O autor prossegue com a descrição das ruas do Passeio ("Uma rua principal nascia à entrada do Passeio e ia morrer entre duas pirâmides e diante de uma pequena cascata." - MACEDO, 2005, p.103), mencionando inclusive o emprego de espécies tropicais nos canteiros, que ostentavam "O tesouro de mimosos e floridos arbustos e a vegetação tropical, representada por árvores que haviam de ser corpulentas e frondosas, e que teriam de oferecer sombra e frescor ainda nas horas canhosas do dia." (MACEDO, 2005, p.103) Os dois pequenos lagos artificiais e as pirâmides de cantaria também não escapam ao olhar arguto do escritor. Sobre estas últimas, afirma: "Uma das pirâmides tinha a inscrição: 'À Saudade do Rio'. A outra: 'Ao amor do Público'." (MACEDO, 2005, p.103) A descrição do outeiro ou cascata é bastante minuciosa:

"O outeiro fora todo formado de pedras sobrepostas como ao acaso, mas com admirável efeito, rebentando dentre elas ervas e arbustos apropriados. Algumas aves graciosas feitas de bronze pousavam sobre as pedras e soltavam dos bicos água cristalina, que se precipitava mais murmurante que ruidosa. Quase na base do outeiro, dois jacarés também de bronze, parecendo recrear-se entrelaçados fora do seu ninho, mostravamse soberbos, lançando pelas bocas abertas cópia d'água claríssima, que ia com a que deitavam as aves ajuntar-se em um tanque semicircular que rodeava a cascata, e onde se reproduziam as imagens dos jacarés. Sobre o cume do outeiro, enfim, elevava-se um magnífico coqueiro de ferro, pintado ao natural, e tendo mais de vinte palmos de altura." (MACEDO, 2005, p.103-4)

Joaquim Manuel de Macedo escreve ainda sobre o terraço ao qual se tinha acesso por quatro escadas de pedra - duas centrais e contíguas à cascata e duas nas extremidades. Para Macedo, o terraço era "espaçoso e cheio de elegância", permitindo a observação da natureza. Era avarandado e lajeado de mármore, possuindo uma "grossa parede" que "o defendia dos ímpetos arrojados do mar". $\bigcirc$ escritor considera, também, como elemento característico do lugar, o parapeito que "o cercava todo, tendo vários alegretes com flores que entremeavam diferentes bancos de pedra comum, e ornados com vasos de mármore" (MACEDO, 2005, p.105).

Depois de descrever detalhadamente o antigo Passeio Público, o escritor aborda todo o processo de deterioração e de abandono que se seguiu à sua inauguração, resultando na necessidade de uma reforma expressiva, efetuada segundo proposta paisagística de Glaziou em meados do século XIX: 
"A planta apresentada ao governo, e por este aprovada, representa um jardim no gênero inglês, hoje admitido em todo o mundo como o mais natural, o mais livre, e que produz mais agradáveis e completas ilusões.

O antigo sistema de alamedas em linha reta e de maciços regulares e uniformes é completamente abandonado." (MACEDO, 2005, p.126)

O autor compara inevitavelmente as linhas curvas, à inglesa, da proposta de Glaziou, às linhas retas do projeto original de Valentim - abandonadas pelo paisagista já sob influência do Ecletismo e não mais do lluminismo do século anterior.

Em outras obras, como em $\bigcirc$ moço loiro, romance lançado em 1845, Joaquim Manuel de Macedo chega a mencionar o Passeio Público, como local frequentado por uma das personagens nas tardes de quinta-feira (MACEDO, s.d., p.15) - era um lugar aonde se ia à tarde, para passear ou se distrair, aparecendo no romance com a função de área de lazer. Em A luneta mágica (1869), Macedo apresenta uma descrição romantizada desse jardim, já transformado pelo projeto de Glaziou:

"Entrei no Passeio Público, e com apressada curiosidade fui vendo e gozando os deleitosos quadros da relva verdejante, dos grupos de arbustos graciosos, das árvores gigantes, das correntes d'água, das pontes, do outeiro dos jacarés, do terraço que se torna admirável pela vista das montanhas, dos rochedos e do mar, das fortalezas e das ilhas, das praias e da cidade formosa, mas recreio da cidade ofuscadora, a que demora fronteira." (MACEDO, s.d., p.44)

Há nesse fragmento do romance a menção às áreas gramadas, aos arbustos, às árvores de grande porte, às águas em cascata, às pontes, ao outeiro, à paisagem do entorno, de modo condizente com a realidade observada pelo escritor. A descrição assume um tom poético, mas de forma alguma perde, neste caso, seu vínculo com o espaço real.

Entre os romancistas do século XIX, não foi apenas Joaquim Manuel de Macedo que incluiu o Passeio Público em suas obras. Também o fizeram escritores da categoria de José de Alencar e de Machado de Assis. Em A pata da gazela, Amélia e sua mãe entram no Passeio e desaparecem "na curva de uma das alamedas do parque, em direção ao lago" (ALENCAR, s.d., p.18) - neste caso, não é necessário sequer verificar o ano de publicação do romance (que ocorreu em 1870) para concluir que o Passeio visitado é aquele modificado segundo o traçado de Glaziou, uma vez que não existiam alamedas em curva no projeto de Valentim. Nesse mesmo romance, Alencar menciona as alamedas recobertas com fina areia e a existência de um lago entre as árvores (ALENCAR, s.d., p.19) - elementos característicos do espaço real, conhecido pelo escritor. Em A viuvinha (1857), José de Alencar se refere a esse espaço apenas como local de passagem: "Jorge ganhou a Rua da Lapa, seguiu pelo Passeio Público, e dirigiu-se à Praia de Santa Luzia" (ALENCAR, s.d., p.14), revelando ser parte de um percurso possivelmente feito pelo próprio escritor.

Machado de Assis, por sua vez, faz do Passeio Público o local de reencontro da protagonista de Helena (1876) com seu pai, que acreditava estar morto:

"Um sábado, porém, tinha Helena doze anos, vindo ambas do colégio, parou o carro defronte do Passeio Público. Vi-as descer e entrar. Levado por um impulso irresistível, 
entrei também. Queria contemplá-las de longe, sem Ihes falar; mas a resolução estava acima das minhas forças. Que pai não faria outro tanto? No lugar mais solitário do Passeio, corri para Helena. Vendo-me, a menina pareceu não reconhecer-me logo; mas tentou um pouco, recuou espavorida e agarrou-se à mãe, abraçando-a pela cintura. Conheci que não estava ali um pai, mas um espectro que regressava do outro mundo. la afastar-me, quando ouvi a voz de Helena perguntar à mãe: 'Papai?'." (ASSIS, 1997, vol.I, p.378)

Em Memórias Póstumas de Brás Cubas (1881), mais uma vez o Passeio é referido como lugar de encontro ou reencontro (Brás Cubas encontra Quincas Borba no Passeio Público do Rio de Janeiro e esse episódio é mencionado e referido várias vezes ao longo da narrativa), caracterizando a sociabilidade propícia do lugar (v. ASSIS, 1997, vol. I).

Em Dom Casmurro (1899), o protagonista, Bentinho, entra no Passeio Público e faz observações sobre os seus usuários e sobre algumas de suas características:

"Entramos no Passeio Público. Algumas caras velhas, outras doentes ou só vadias espalhavam-se melancolicamente no caminho que vai da porta ao terraço. Seguimos para o terraço. Andando, para me dar ânimo, falei do jardim:

- Há muito tempo que não venho aqui, talvez um ano.

- Perdoe-me, atalhou ele, não há três meses que esteve aqui com o nosso vizinho Pádua; não se lembra?

- É verdade, mas foi tão de passagem..." (ASSIS, 1997, vol.I, p.834)

Mais adiante, revela a existência de mendigos junto ao portão:

"Ao portão do Passeio, um mendigo estendeu-nos a mão. José Dias passou adiante, mas eu pensei em Capitu e no seminário, tirei dois vinténs do bolso e dei-os ao mendigo." (ASSIS, 1997, vol. I, p.837)

Neste caso, é muito provável que o autor, Machado de Assis, estivesse registrando na literatura um dado da realidade: a característica social dos ocupantes do entorno dessa área arborizada da cidade.

Ainda em um dos capítulos finais do romance, Machado de Assis menciona o Passeio Público do Rio de Janeiro como um lugar frequentado à tarde por Bentinho e Escobar - do mesmo modo que Joaquim Manoel de Macedo faz em O moço loiro, indicando o horário de visitação:

"(...) Sobretarde descíamos à praia ou íamos ao Passeio Público, fazendo ele os seus cálculos, eu os meus sonhos." (ASSIS, 1997, vol.I, p.914)

Essa observação, entretanto, parece contrária à de muitos relatos de viagem ainda que se considere o fato de que o romance foi publicado em 1899, ou seja, dez anos depois de instaurada a República. De acordo com os viajantes europeus, mesmo depois da reforma de Glaziou, o Passeio Público do Rio de Janeiro continuou sendo pouco frequentado. Para Hugo Segawa, isso se devia, em parte, à contradição entre a ideia de um jardim público, onde a aristocracia e a burguesia poderiam se encontrar, ocupando um lugar comum, e o meio colonial escravocrata em que foi inserido o jardim (SEGAWA, 1996, p.108). É bem provável que os próprios escritores, como Joaquim Manuel de Macedo, José de Alencar e Machado de Assis, fossem frequentadores 
contumazes do Passeio Público e por isso a inserção desse espaço em seus romances. Como escritores e romancistas, talvez fossem capazes de apreciar devidamente, ou com uma sensibilidade mais apurada, a beleza dessa área arborizada do Rio de Janeiro além de reconhecer seu valor paisagístico ou as visões de paisagem que propiciava. Ao registrar sua existência na literatura, esses autores evidenciam seu lugar na paisagem real e seu significado para a sociedade da época.

\section{O PASSEIO PÚBLICO NA PINTURA}

A pintura de paisagens no Brasil era ainda rara em princípios do século XIX. Nesse sentido foi significativa a contribuição dos pintores viajantes como Thomas Ender e Rugendas - o próprio Debret, pintor de costumes e de história, também elaborou diversos panoramas e vistas de vilas e cidades brasileiras. Mas praticamente não havia pintores brasileiros interessados no tema de paisagens e menos ainda de paisagens do Brasil. Exceção à regra foi Leandro Joaquim, que ainda em fins do século XVIII retratou a Igreja da Glória (Vista da Igreja da Glória, 1790) em uma paisagem de mar, morros e construções junto à praia, o Largo do Paço (Revista Militar no Largo do Paço, 1790), com grande destaque dado ao espaço livre central, e os arcos da Carioca na paisagem (em Vista da Lagoa do Boqueirão e dos Arcos da Carioca, 1790).

Dos pintores viajantes, quem deixou um registro importantíssimo do Passeio Público em suas aquarelas foi Thomas Ender. $O$ pintor austríaco, que veio ao Brasil com a comitiva da princesa Leopoldina, em 1817, ficando impressionado com a luz dos trópicos, como assinala Gilberto Ferrez (1976), e conferindo assim a muitas de suas aquarelas um tom entre o amarelo vivo e o dourado, com uma ênfase também muito expressiva à vegetação tropical, retratou o Passeio Público, ainda com o projeto de Valentim, em pelo menos duas obras. Na primeira, executada do ponto de vista de quem acessa o Passeio, registra a fonte dos jacarés à distância, com o Pão de Açúcar ao fundo, à direita do observador, e uma aleia de árvores frondosas sombreando o caminho principal e ocultando as duas pirâmides. Na segunda, o pintor volta-se para trás e registra a imagem das pirâmides com a aleia já a certa distância - ao fundo é possível ver a igreja da Lapa e o convento de Santa Teresa, à esquerda do observador. $\bigcirc$ artista estabelece uma relação entre esse espaço livre e a paisagem do Rio de Janeiro; trabalha, como em muitas de suas aquarelas, com um tom entre o amarelo e o dourado, e enfatiza a vegetação e o relevo circundante.

Outro artista que retratou o Passeio Público na primeira metade do século XIX, mais especificamente em 1847, foi Alfred Martinet, colocando uma das pirâmides do centro de sua obra, a confluência de dois caminhos sem pavimentação e alguns usuários no primeiro plano, um dos pavilhões à esquerda do observador - parcialmente ocultado pela vegetação - e uma sequência de árvores de grande porte à direita de quem olha. A imagem é de um lugar muito simples, com ruas de terra e canteiros delimitados por cercas de madeira aparentemente improvisadas, revelando 
a ausência de manutenção do espaço. Martinet retratou também o terraço com a vista do mar e os morros ao longe, e a mureta com vasos de plantas, descrita por Joaquim Manuel de Macedo. Apesar de não ser datada, a obra é importante por registrar a paginação do piso do terraço do projeto original, bem como as características do pequeno, mas extenso, muro que separava o terraço do mar.

Um desenho de autoria ilegível (Obelisco do Jardim Público do Rio de Janeiro), mas com data aproximada de 1836 a 1839, que integra o acervo da Fundação Biblioteca Nacional, mostra a relação entre as duas pirâmides e o caminho principal - retilíneo e plenamente arborizado. A ausência de manutenção é patente nesse desenho. Ainda que não se trate de uma pintura, é outro registro importante desse espaço do ponto de vista histórico e não poderia deixar de ser mencionado.

Há também uma imagem do Passeio Público do Rio de Janeiro (do mesmo modo que a imagem do Outeiro da Glória, a da Entrada da baía e a da Praça Quinze) no interior da Casa Esperança em São Sebastião - um sobrado do século XVIII, que apresenta diversas pinturas decorativas no teto e na parede de seus cômodos, tombado pelo IPHAN em 1955; provavelmente outra das raras representações por artista brasileiro da paisagem do Brasil oitocentista e no interior de uma construção, demonstrando a valorização desse espaço pela sociedade, de um modo geral, e pelo proprietário, em particular, que ao encomendar essa pintura desejou a visão da paisagem do Passeio por meio de uma representação pictórica.

Esses exemplos ratificam a importância desse espaço livre público para a cidade do Rio de Janeiro e para a sociedade da época, correspondendo a documentos relevantes e reveladores das características dessa área arborizada e ajardinada, muitas vezes anteriores às reformas propostas por Glaziou.

\section{O PASSEIO PÚBLICO NA FOTOGRAFIA}

No Brasil, os primeiros fotógrafos paisagistas iniciaram suas atividades em meados do século XIX (CARVALHO, 1991, p.203). Já em 1850, Charles de Forest Fredericks anunciava no Correio Mercantil a venda de vistas do porto do Recife (KOSSOY, 1980, p.33). De acordo com Vânia Carvalho (1991, p.203), a produção de paisagens contava com um público relativamente restrito no Brasil, composto em parte por viajantes e imigrantes residentes no país, que enviavam, a seus amigos e parentes, imagens do lugar onde viviam e trabalhavam.

Entre os fotógrafos que se dedicaram ao gênero de paisagens, retrataram o Passeio Público na segunda metade do oitocentos: Revert Henrique Klumb (em 1860), Leuzinger (em 1860), Augusto Stahl (em 1865), Marc Ferrez (em 1890), e Juan Guitierrez (em 1893).

O trabalho de Klumb, fotógrafo alemão que chegou ao Brasil em 1852, é de grande importância para a História do Paisagismo no Brasil. Além das paisagens urbanas registradas em vistas e panoramas, Klumb fotografou o Jardim Botânico do Rio de Janeiro - em particular a aleia de palmeiras imperiais, o lago, as cascatas, a vegeta- 


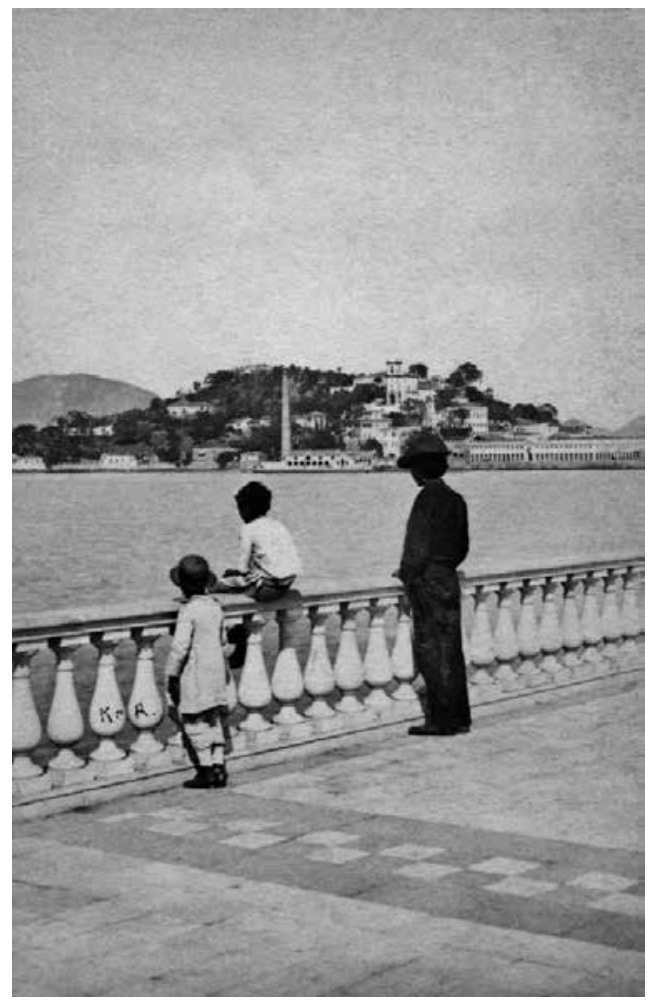

Figura 2 - O terraço do Passeio Público do Rio de Janeiro, com vista para o mar. Glória, c. 1861. Rio de Janeiro - RJ.

Crédito: Revert Henrique Klumb / Coleção Gilberto Ferrez / Acervo Instituto Moreira Salles.

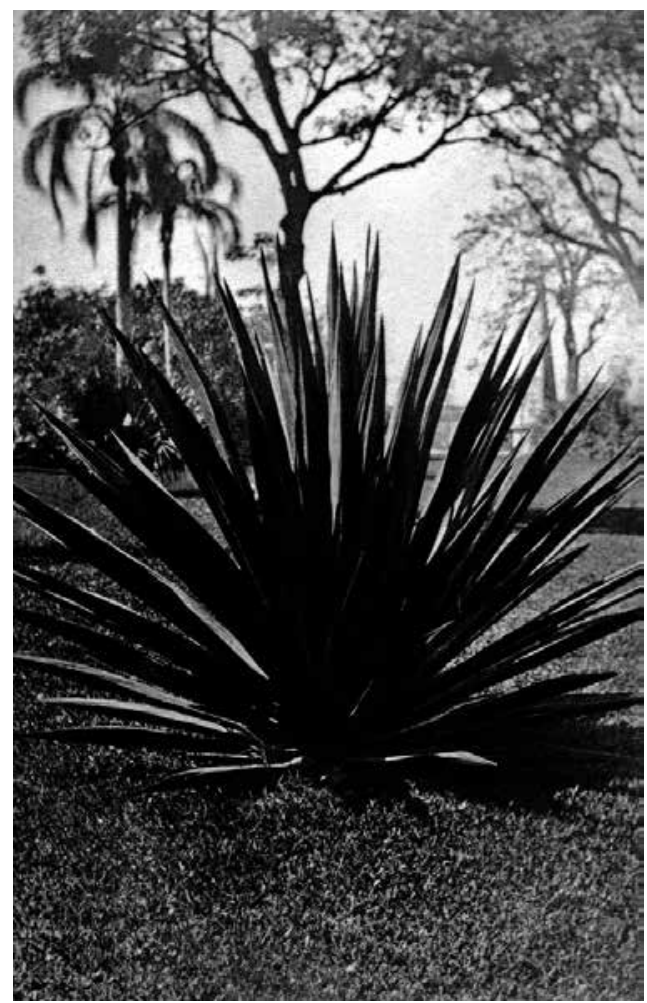

Figura 3 - Detalhes da vegetação tropical retratados por Klumb. Passeio Público, c. 1861. Rio de Janeiro - RJ. Crédito: Revert Henrique Klumb / Coleção Gilberto Ferrez / Acervo Instituto Moreira Salles.

ção exuberante e os próprios usuários do jardim; fotografou algumas praças do Rio de Janeiro, como a Praça no Alto da Boa Vista, árvores plantadas ao longo da rua do Mosteiro de São Bento, o amplo espaço livre em frente ao Paço, o chafariz projetado pelo mestre Valentim e o Passeio Público.

Os usuários desse espaço livre - homens descalços, mulheres com vestidos longos e o rosto coberto por véus, crianças -, o terraço do Passeio Público, voltado para o mar, com seus bancos de mármore, as duas pirâmides, o chafariz do terraço, as pontes e luminárias, o café e detalhes da vegetação foram perfeitamente registrados por Klumb em sua obra. Mas apesar do fato de serem as imagens datadas de 1860 (especialmente as que integram o acervo da Fundação Biblioteca Nacional), constata-se que o Passeio retratado já é aquele alterado por Glaziou, marcado pelas linhas curvas dos canteiros e, portanto, posterior a 1862.

George Leuzinger foi um fotógrafo suíço que veio ao Brasil em 1832, instalando-se no Rio de Janeiro, onde abriu um ateliê fotográfico em 1860. Em uma de suas imagens do Passeio Público, de 1865, Leuzinger destaca a exuberância das espécies tropicais empregadas pelo paisagista, em meio às quais se destacam as duas pirâmides do projeto de Valentim. Nesse momento a manutenção das áreas ajardinadas e das áreas 
de circulação parecia adequada. Todos os elementos da composição se apresentam ordenados ao observador.

Augusto Stahl, fotógrafo que nasceu em Bérgamo - comuna italiana na região da Lombardia, chegou ao Brasil em 1853, instalando-se inicialmente no Recife e, na década de 1860, no Rio de Janeiro. As fotografias do Passeio Público datam de 1865 e destacam mais uma vez o traçado curvilíneo do projeto de Glaziou. Entre elas há uma imagem de grande valor estético, com o enquadramento das pirâmides em perspectiva, como se acompanhassem a curva do lago, e com grande destaque dado à vegetação.

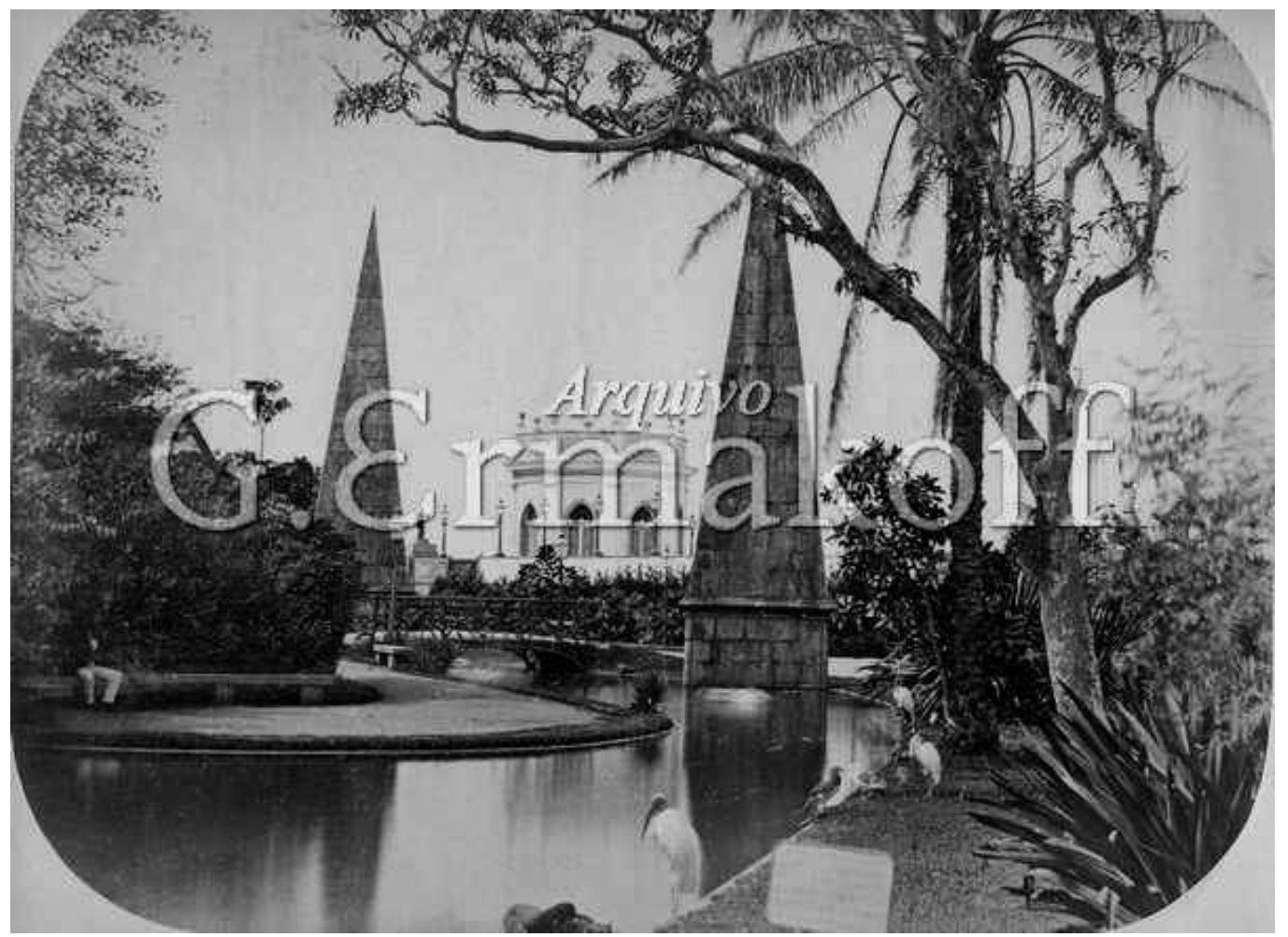

Figura 4 - As duas pirâmides e a curva do lago em meio à vegetação. Uma visão estética do Passeio Público. Passeio Público, c. 1865. Rio de Janeiro - RJ.

Crédito: Augusto Stahl / Arquivo G. Ermakoff.

Marc Ferrez foi um fotógrafo brasileiro fascinado pelas paisagens do Brasil, tendo registrado a imagem de várias cidades brasileiras no século XIX - inclusive as do norte do país, como Belém e Manaus. No Rio de Janeiro retratou diversas vistas e panoramas, assim como as ruas, os edifícios e os espaços livres. Em uma das fotografias do Passeio Público, enquadrou a pequena ponte sobre o lago, as luminárias, a vegetação exuberante e os morros ao fundo, compondo uma paisagem única com os elementos naturais da cidade - neste caso os morros - e os elementos do Passeio Público. Em uma vista do bairro da Lapa, Ferrez registra a ruptura do tecido urbano na área do Passeio e a expressiva massa de vegetação que o compunha, destacando-se entre as construções e junto ao mar. 


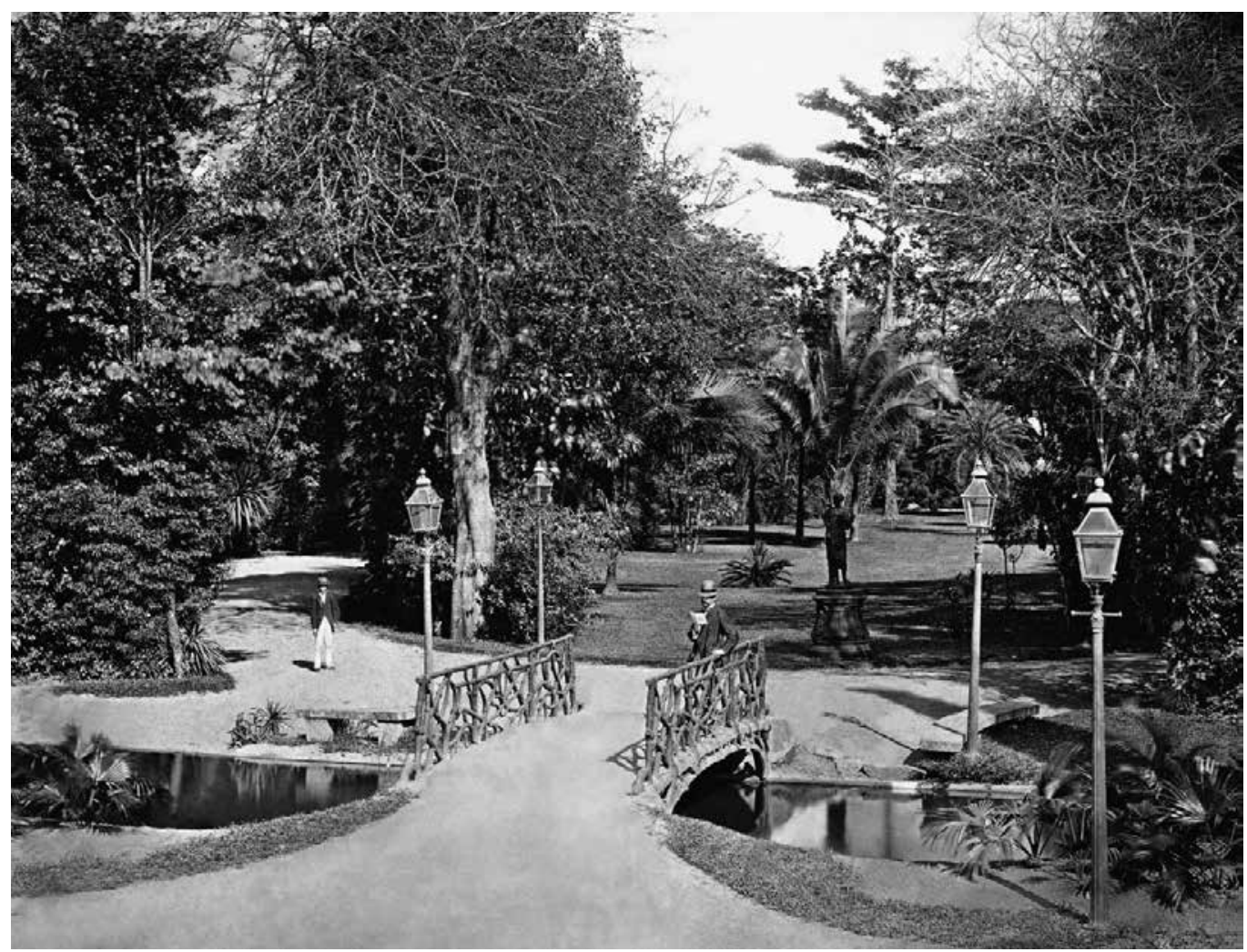

Figura 5 - A ponte sobre o lago e a vegetação exuberante do Passeio Público. Passeio Público, c. 1870. Rio de Janeiro - RJ.

Crédito: Marc Ferrez / Coleção Gilberto Ferrez/ Acervo Instituto Moreira Salles.

Juan Gutierrez, fotógrafo espanhol que retratou o Rio de Janeiro nas décadas de 1880 e 1890, era "panoramista". A maior parte de suas fotografias corresponde, portanto, a vistas panorâmicas. Mas, além dos panoramas, há em seu trabalho imagens de edifícios e de espaços livres públicos, como o Passeio Público - retratado pelo artista em 1893, já com o projeto de Glaziou, com as duas pirâmides do projeto original de Valentim em destaque na composição fotográfica.

Ainda do ponto de vista paisagístico, é importante ressaltar que nos panoramas de Gutierrez (como em Panorama visto de Santa Teresa, de 1892, ou em Panorama do Rio tomado da Igreja de São Francisco de Paula, de 1893), fica evidente a difusão das palmeiras no espaço urbano depois do bem-sucedido plantio de palmeiras imperiais no Jardim Botânico. Esse elemento se torna parte da paisagem de um modo marcante - seja nos espaços livres públicos, seja atrás das casas, seja em frente às residências, seja em meio às construções.

Observa-se, assim, que os fotógrafos paisagistas não estavam interessados apenas em retratar vistas e panoramas. Espaços livres como o Passeio Público - e o Jardim Botânico - também atraíam a atenção, seja pelo que representavam no tecido urbano, seja pela profusão de espécies vegetais que valorizavam a composição fotográfica. Graças 


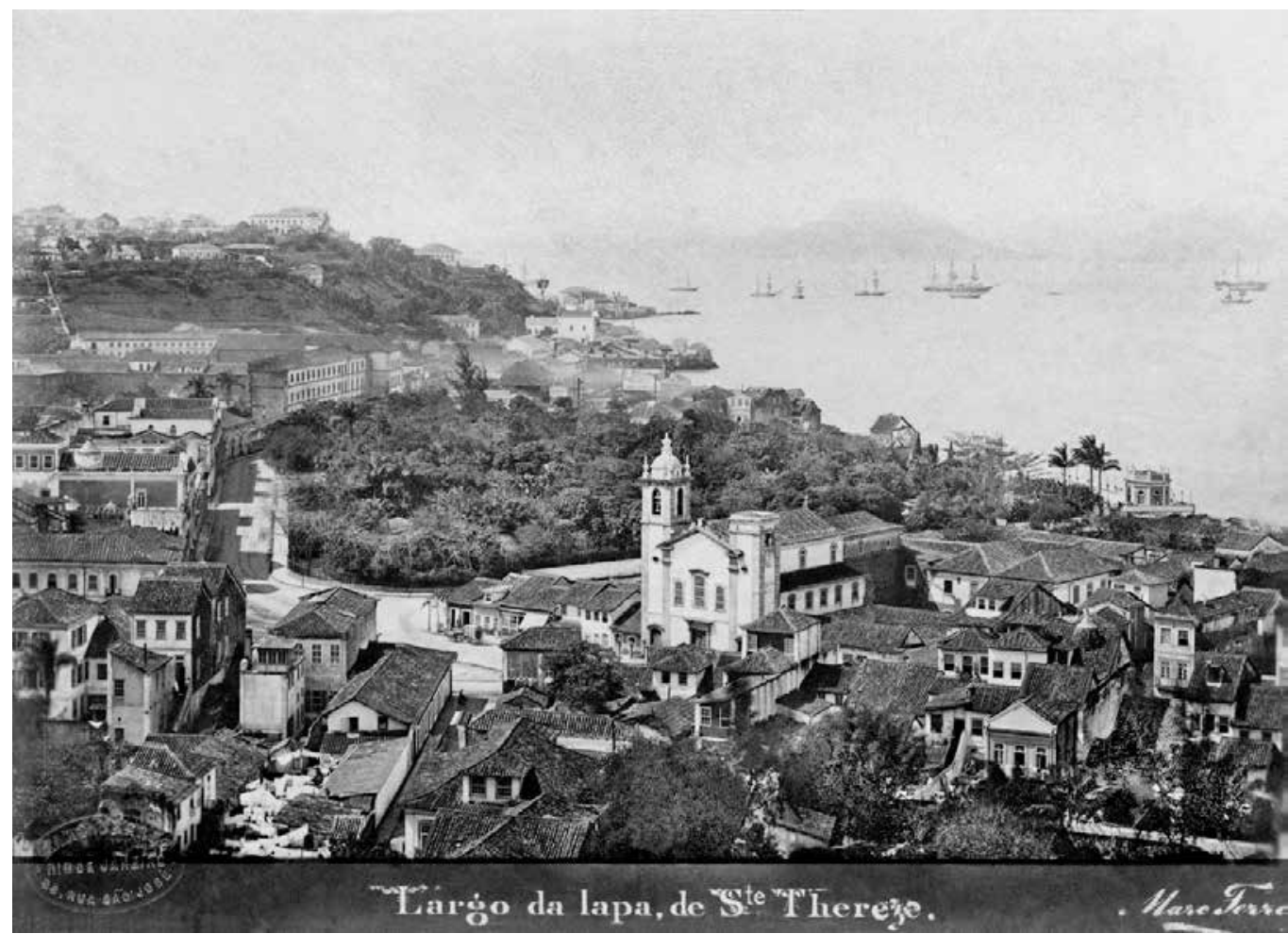

Figura 6 - O Passeio Público do Rio de Janeiro no tecido urbano. A massa de vegetação em destaque em meio ao casario. Largo da Lapa, visto de Santa Teresa, c. 1885. Rio de Janeiro - RJ.

Crédito: Marc Ferrez / Coleção Gilberto Ferrez/ Acervo Instituto Moreira Salles.

a isso, temos documentos importantes desses espaços no modo como se apresentavam na segunda metade do século XIX.

Se "uma única imagem contém em si um inventário de informações acerca de um determinado momento passado", como assinala Boris Kossoy (2008, p.133), imagine-se, então, o valor de um conjunto de fotografias de um mesmo lugar, elaboradas em épocas distintas. A análise comparativa dessas imagens revela não apenas as transformações paisagísticas, como também mudanças no uso do espaço.

\section{CONCLUSÃO}

As representações do Passeio Público do Rio de Janeiro no século XIX correspondem a apenas um exemplo da importância da literatura, da pintura e da fotografia para a construção da História do Paisagismo no Brasil e da História da Paisagem Brasileira. Percurso semelhante poderia ser feito com relação ao Jardim Botânico no século XIX (que além de ser muito citado pelos viajantes em seus relatos pela surpreendente aleia de palmeiras imperiais, aparece no romance, na pintura e em muitas fotografias do período). Temos localizado também várias imagens de praças e de espaços livres públicos de valor histórico e descrições de ruas, largos e jardins na literatura. 
Percebe-se, assim, que essas representações podem ser empregadas não apenas nos estudos da paisagem de um modo geral e de suas transformações ao longo do tempo, mas também na análise das modificações e na caracterização de determinados espaços livres da área urbana em períodos diversos.

Gilberto Freyre foi um dos primeiros estudiosos a chamar a atenção de historiadores e pesquisadores para o valor histórico e documental de fontes como os relatos de viagem, os anúncios de jornal, os textos literários e a produção iconográfica. É importante trazer essa contribuição para o campo do Paisagismo, ampliando as possibilidades de pesquisa e descoberta na construção da história de nossas paisagens. 


\section{Nota}

$1 \bigcirc$ presente trabalho, realizado com apoio do CNPq (Conselho Nacional de Desenvolvimento Científico e Tecnológico - Brasil), apresenta alguns dos primeiros resultados da pesquisa intitulada A Cidade nas Artes - da Colônia ao Império, desenvolvida por Solange de Aragão, junto ao Núcleo de Estudos da Paisagem, sob a supervisão do Prof. Dr. Euler Sandeville Júnior, integrando sua Linha de Pesquisa Estudos das Artes, Natureza e Manifestações Culturais no Urbano.

\section{Bibliografia}

ALENCAR, José de. A pata da gazela. Texto proveniente da Fundação Biblioteca Nacional (http://www.bn.br). Disponível em: http://www.dominiopublico.gov.br. Acesso em 2011.

A viuvinha. Texto proveniente da Fundação Biblioteca Nacional (http://www.bn.br). Disponível em: http://www.dominiopublico.gov.br. Acesso em 2011.

ASSIS, Machado de. Obra completa. Rio de Janeiro: Nova Aguilar, 1997.

CARVALHO, Vânia Carneiro de. A representação da natureza na pintura e na fotografia brasileiras do século XIX. In: FABRIS, Annateresa (Org.). Fotografia: usos e funções no século XIX. São Paulo: Edusp, 1991, p. 199-231.

ERMAKOFF, George. Juan Gutierrez. Imagens do Rio de Janeiro, 1892-1896. Rio de Janeiro: Capivara, 2001.

FERREZ, Gilberto. O Brasil de Thomas Ender, 1817. Rio de Janeiro: Fundação João Moreira Salles, 1976.

. O Rio antigo do fotógrafo Marc Ferrez. Paisagens e tipos humanos do Rio de Janeiro, 1865-1918. São Paulo: Ex Libris, 1984

FLEIUSS, Max. História da cidade do Rio de Janeiro. São Paulo: Melhoramentos, 1928.

GRANT, Andrew. History of Brazil. Londres: Henry Colburn, 1809.

KOSSOY, Boris. Fotografia e paisagem: $\bigcirc$ explícito e o oculto nas representações fotográficas. Revista de Comunicação e Linguagens (39), Lisboa, jun.2008, p.133-142.

. Origens e expansão da fotografia no Brasil - século XIX. Rio de Janeiro: FUNARTE, 1980.

LAGO, Bia Corrêa do. Augusto Stahl. Obra completa em Pernambuco e Rio de Janeiro. Rio de Janeiro: Capivara, 2001.

MACEDO, Joaquim M. de. A luneta mágica. Texto proveniente da Fundação Biblioteca Nacional (http://www.bn.br). Disponível em: http://www.dominiopublico.gov.br. Acesso em 2011.

Um passeio pela cidade do Rio de Janeiro. Texto proveniente da Biblioteca Básica do Senado Federal (Brasília: Senado Federal, 2005). Disponível em: http://www.dominiopublico.gov.br. Acesso em 2011.

O moço loiro. Texto proveniente da Fundação Biblioteca Nacional (http://www.bn.br). Disponível em: http://www.dominiopublico.gov.br. Acesso em 2011.

MARX, Murillo. Cidade brasileira. São Paulo: Melhoramentos, 1980.

SANTUCCl, Jane. O passeio público no século XX: "Novos" sujeitos, usos e atribuições. Leituras paisagísticas: Teoria e práxis (1): (Re)construindo a paisagem do Passeio Público, historiografia e práticas projetuais. Rio de Janeiro: EBA/UFRJ, 2006.

SEGAWA, Hugo. Ao amor do público: Jardins no Brasil. São Paulo: Studio Nobel/ Fapesp, 1996.

VASQUEZ, Pedro Karp. Revert Henrique Klumb. Rio de Janeiro: Capivara, 2001.

WAGNER, Robert. Viagem ao Brasil nas aquarelas de Thomas Ender. Petrópolis: Kapa Editorial, 2000. 
